\title{
O DIREITO INTERNACIONAL DOS REFUGIADOS EM XEQUE: REFUGIADOS AMBIENTAIS E ECONÔMICOS
}

\author{
Ana Paula da Cunha ${ }^{1}$
}

\section{RESUMO}

O presente artigo tem por escopo uma breve análise sobre o documento legal de excelência do Direito Internacional dos Refugiados, a Convenção Relativa ao Estatuto dos Refugiados de 1951, bem como questionar a sua adequação em face da nova realidade contemporânea no tocante à problemática dos refugiados.

Advoga-se, neste sentido, a necessidade de ampliação deste diploma diante de dois exemplos - não exaustivos - de grupos de migrantes forçados que deveriam gozar da proteção do instituto universal do refúgio e que não o fazem por não se enquadrarem na definição formal trazida pela Convenção de 1951, quais sejam, os refugiados ambientais e os refugiados econômicos, estes últimos também chamados refugiados da fome.

\section{ABSTRACT}

This article aims at a brief analysis of the legal document on excellence of the International Refugee Law, the Convention Relating to the Status of Refugees of 1951, as well as questioning its adequacy in light of new contemporary reality of refugee problems.

Thus, the extension of this law is advocated in face of two examples non exhaustive - of groups of forced migrants who should be under protection of the Universal Institute for Refugees but who are not protected because they do not comply with the formal definition brought by the Convention of 1951, i.e., the environmental and the economic refugees, these last also called hunger refugees.

\footnotetext{
${ }^{1}$ Acadêmica do 40. ano de Direito da UFPR e do 40. ano de Relações Internacionais do Unicuritiba. Monitora de Direito Internacional Público (UFPR).
}

Revista Brasileira de Direito Internacional, Curitiba, v.8, n.8, jul/dez.2008 
Indicadores: Convenção Relativa ao Estatuto dos Refugiados; refugiados ambientais; refugiados econômicos.

Keywords: Relating to the Status of Refugees; environmental refugees; economic refugees.

O homem pode perder todos os chamados direitos do homem, sem perder a qualidade essencial de homem, sua dignidade humana. Só a perda da própria comunidade é que o expulsa da humanidade. Hannah Arendt.

\section{INTRODUÇÃO}

Consoante assertiva de José Fischel de ANDRADE, o fenômeno de o indivíduo restar perseguido no interior do próprio Estado é tão antigo quanto a própria humanidade; contudo, a regulamentação jurídica da situação de refugiado dá-se tão somente no século $X X^{2}$. É, pois, a partir da Liga das Nações, que têm início os esforços institucionais para a estruturação de um arcabouço político-jurídico de proteção aos refugiados, como se investigará mais adiante.

É certo que até os momentos que antecederam a Primeira Grande Guerra, não havia uma necessidade pulsante de uma mobilização internacional no sentido de assegurar a proteção a indivíduos perseguidos no interior de seus próprios Estados. Isto porque se faziam suficientes os institutos do asilo (que guarda em relação ao refúgio a semelhança de ser um instituto de proteção à pessoa humana perseguida no interior do seu próprio Estado, diferenciando-se, contudo, ao se constituir de um direito do Estado, ou seja, de ser concedido com base na discricionariedade estatal e não em acordos internacionais criadores de direitos subjetivos para os indivíduos) e da extradição, ou seja, a possibilidade de devolução de um indivíduo ao país em que ele tenha cometido um crime, a fim de que seja julgado ou cumpra pena.

\footnotetext{
${ }^{2}$ ANDRADE, José Fischel de. Direito Internacional dos refugiados: evolução histórica (19211952).p. 3.
}

Revista Brasileira de Direito Internacional, Curitiba, v.8, n.8, jul/dez.2008 
A Liga das Nações foi estruturada a partir de uma perspectiva Idealista, isto é, de reafirmação da crença na natureza boa do homem e na possibilidade de pacificação do sistema internacional por meio do Direito. ${ }^{3} \mathrm{E}$ é neste contexto que a Liga das Nações trata de buscar soluções para a situação dos refugiados.

Contudo, como advoga FISCHEL, embora a organização tenha o mérito de iniciar um tratamento institucional para o drama dos refugiados, ela empreendeu seus esforços de maneira tão somente empírica, não abarcando as estruturas políticas e também jurídicas inerentes à questão ${ }^{4}$, o que fica claro quando se observa que a Liga não procurou desenvolver sequer uma definição oficial de quem pudesse ser considerado "refugiado", tratando de oferecer proteção aos grupos sociais forçosamente deslocados de seus países de modo casuístico e pontual, isto é, a grupos específicos de refugiados.

Fato é que a Liga das Nações não conseguiu empreender uma solução definitiva para a situação dos refugiados. Os sucessivos fracassos podem ser explicados, por exemplo, pelo baixo número de Estados-partes dos acordos internacionais sobre o tema. Ainda, pela proliferação excessiva de órgãos que tratavam de grupos específicos de refugiados, o que dificultava a coordenação de esforços para um tratamento sistemático da problemática, já que não havia um organismo que centralizasse as ações referentes. Ademais, saliente-se que a Liga das Nações possuía uma estrutura bastante sensível às pressões políticas de seus Estados-membros, já que não configurava uma autêntica federação de Estados autônomos, mas uma associação de Estados soberanos.

A Segunda Grande Guerra veio a acentuar a dramática situação dos refugiados, o que se agravava pela ausência de um centro de poder capaz de assegurar um adequado tratamento para a questão.

Finalmente, em 28 de julho de 1951, já sob a égide da Organização das Nações Unidas, também de inspiração Idealista, materializou-se o esforço empreendido desde o começo do século XX, a partir da Liga das Nações, para a consolidação de um efetivo Direito Internacional dos Refugiados: restava elaborada a Convenção Relativa ao Estatuto dos Refugiados.

\footnotetext{
${ }^{3}$ SALDANHA, Eduardo. Teoria das Relações Internacionais. p. 66.

${ }^{4}$ ANDRADE, José Fischel de. Op cit. p. 23.
}

Revista Brasileira de Direito Internacional, Curitiba, v.8, n.8, jul/dez.2008 


\section{A CONVENÇÃO RELATIVA AO ESTATUTO DOS REFUGIADOS} DE 1951

A importância da Convenção de 1951 é inegável. O referido documento é um marco no Direito Internacional, pois se trata do primeiro acordo multilateral e de âmbito universal a dispor acerca de aspectos essenciais que dizem respeito aos refugiados. ${ }^{5}$ Marca, portanto, o comprometimento da sociedade internacional com a devida responsabilidade para com este grupo social tão vulnerável.

É de se observar que a Convenção reconhece a dimensão mundial da questão dos refugiados e a necessidade da difusão de uma solidariedade internacional no trato da problemática, advogando notadamente a partilha da responsabilidade entre os Estados.

A importância deste diploma de Direito Internacional é marcante ainda no que diz respeito ao fato de ele conferir verdadeiros direitos subjetivos fundamentais aos refugiados, como o direito à educação, à saúde, à integralidade do núcleo familiar, entre outros.

Grande avanço significou esta convenção, ainda, devido ao fato de elaborar uma definição jurídica de refugiado e, a partir dela, organizar uma estrutura de coordenação dos esforços no trato da problemática, encabeçados pelo Alto Comissariado das Nações Unidas para Refugiados (ACNUR), criado por meio da Resolução 319 da Assembléia Geral das Nações Unidas, em dezembro de $1949 .{ }^{6}$

O ACNUR foi criado com a função precípua de proteger os refugiados e buscar soluções permanentes para a temática. É interessante perceber que o ACNUR foi instituído tendo um tempo determinado de existência (três anos, a partir de janeiro de 1951). Acreditava-se que a questão dos refugiados seria pontual e transitória.

\footnotetext{
${ }^{5}$ UNHCR. La Convention de 1951 relative au statut des réfugiés : questions et réponses. p. 6.

${ }^{6}$ UNHCR. Introduction à la protection internationale: protèger les personnes relevant de la compétence du HCR. Module d'autoformation 1. p. 7.
}

Revista Brasileira de Direito Internacional, Curitiba, v.8, n.8, jul/dez.2008 
O fato é que, dado o caráter continuado do fluxo de refugiados, a agência da ONU foi tendo seu mandato alargado sucessivamente, através de resoluções da Assembléia Geral das Nações Unidas. Finalmente, em 2003, também por meio de resolução, determinou-se que o ACNUR deveria dar prosseguimento aos seus trabalhos até que o problema dos refugiados fosse definitivamente resolvido.

\subsection{CLÁUSULAS DE INCLUSÃO DA CONVENÇÃO DE 1951}

As chamadas cláusulas de inclusão presentes na Convenção de 1951 destinam-se a estabelecer critérios objetivos para o reconhecimento do status de refugiado a um indivíduo demandante da proteção internacional do refúgio.

De acordo com o artigo 1ํ A da Convenção de 1951, refugiado é uma pessoa que:

“... Por fundado temor de perseguição por motivos de raça, religião, nacionalidade, grupo social ou opiniões políticas, encontra-se fora do país de sua nacionalidade e que não pode ou, em virtude desse temor, não quer valer-se da proteção desse país, ou que, se não tem nacionalidade, encontra-se fora do país no qual tinha sua residência habitual em conseqüência de tais acontecimentos, não pode ou, devido ao referido temor, não quer voltar a ele". ${ }^{7}$

A Convenção de 1951 traçou uma definição de refugiado balizada pelo critério do individualismo. Quer dizer, o refugiado não era mais analisado enquanto membro pertencente a um grupo social em específico, como se deu nos primeiros momentos do trato da questão, mas sim enquanto um indivíduo carente de proteção internacional. Como aponta Jean Yves-CARLIER, Presidente do Departamento de Direito Internacional da Universidade Católica de Louvain (Bélgica), a lógica que estava por detrás desta opção pelo individualismo residia no fato de, após a Segunda Grande Guerra, muitos países fecharem suas fronteiras ao ingresso de imigrantes fugidos de seus

\footnotetext{
${ }^{7}$ Convenção Relativa ao Estatuto dos Refugiados de 1951, artigo 1ํA. Grifo nosso.
}

Revista Brasileira de Direito Internacional, Curitiba, v.8, n.8, jul/dez.2008 
países de origem ou de nacionalidade e, assim, em "não podendo o Estado acolher todo um grupo, acolhe um ou outro indivíduo". 8

Num segundo momento, observa-se que o diploma legal emprega termos extremamente subjetivos, o que fica claro na expressão "fundado temor de perseguição", o que dá margem a interpretações que se prestem aos interesses daqueles que realizam os procedimentos de concessão do status de refugiado. Quer dizer, cabe ao próprio Estado de acolhida determinar se um indivíduo tem ou não um fundado temor de perseguição, o que é bastante ilógico, mas compreensível do ponto de vista de uma política realista do Estado. Conforme o ACNUR, contudo, "perseguição" deve ser entendida como ameaças graves, sistemáticas ou repetitivas, à vida e/ou à liberdade do indivíduo. ${ }^{9}$

Frise-se, por fim, que as cláusulas de inclusão são de extrema valia para o processo reconhecimento do refugiado, dado que a partir a inclusão do indivíduo sob a égide de proteção da Convenção de 1951, é possível que ele tenha acesso a verdadeiros direitos subjetivos, como já se antecipou acima (como de acesso aos tribunais do país de acolhida ${ }^{10}$., liberdade religiosa ${ }^{11}$, assistência social $^{12}$ etc), bem como de garantia contra devolução ao país em que sofre perseguições ${ }^{13}$.

\subsection{AS CLÁUSULAS DE EXCLUSÃo E DE CESSAÇÃO DA} CONVENÇÃO DE 1951

A mesma Convenção de 1951, além disto, prevê as chamadas cláusulas de exclusão ${ }^{14}$ e de cessação ${ }^{15}$ do refúgio.

\footnotetext{
${ }^{8}$ Curso de verão sobre refugiados. Instituto Internacional de Direitos Humanos, Strasbourg. 16 de junho de 2008.

9 UNHCR. Introduction à protection internationale... Module d'autoformation 1. op cit. p. 62.

${ }_{11}^{10}$ Artigo 16 da Convenção de 1951.

${ }^{11}$ Artigo 4º da Convenção de 1951.

${ }^{12}$ Artigo 24 da Convenção de 1951.

${ }^{13}$ Artigo 33 da Convenção de 1951.

${ }_{11}^{14}$ Artigo 1‥ , seções D, E e F da Convenção de 1951.

${ }^{15}$ Artigo $1^{\circ}$. , seção $\mathrm{C}$ da Convenção de 1951.
}

Revista Brasileira de Direito Internacional, Curitiba, v.8, n.8, jul/dez.2008 
De acordo com interpretação do ACNUR, as cláusulas de exclusão tocam os indivíduos que preenchem os requisitos do status de refugiado, mas dele não têm necessidade ou não se configuram dele merecedores. ${ }^{16}$

As referidas cláusulas de exclusão, expressas no artigo 1D, E e F, atingem os indivíduos: a) que gozam de proteção de outro organismo das Nações Unidas que não o Alto Comissariado das Nações Unidas para Refugiados (como no caso da Agência da ONU para os refugiados palestinos no Oriente Médio), b) que são considerados pelas autoridades do país de acolhimento como tendo os direitos e obrigações relativos à posse da nacionalidade, c) sobre os quais há "sérias razões para se pensar" que hajam cometido um crime contra a paz, um crime de guerra ou um crime contra a humanidade, um crime grave de direito comum fora do país de acolhida antes de serem nele admitidos como refugiados ou também d) que são culpados por atos contrários aos princípios das Nações Unidas.

No que tange à cessação do status de refugiado, tem-se que, conforme interpretação do próprio ACNUR, o estado de refugiado foi concebido para ser temporário. Isto é, a partir do momento em que o indivíduo não tem mais necessidade de proteção fora de seu país, podendo gozar das mesmas condições que os cidadãos nacionais do país de acolhida ou da proteção do seu país de origem ou de nacionalidade, a ajuda internacional torna-se injustificada ${ }^{17}$, dado o princípio da subsidiariedade desta última.

As hipóteses de cessação da proteção internacional ao refugiado são elencadas no artigo 1C da Convenção de 1951 e são elas: a) o refugiado voltar a valer-se da proteção do país de que é nacional; b) recuperar a nacionalidade, caso a tenha perdido; c) adquirir nova nacionalidade e passar a gozar da proteção do país que a concedeu; d) voltar a estabelecer-se voluntariamente no país que abandonou pelo temor de perseguição; e) cessarem as condições que motivaram a busca pelo refúgio; f) ou, em sendo o refugiado um apátrida, estiver em condições em condições de retornar ao país em que mantinha residência habitual.

\footnotetext{
16 HCNUR. Détermination du statut de réfugié: déterminer qui est un réfugié. Module dáutoformation 2. p. 86.

${ }^{17}$ Ibidem. p. 124.
}

Revista Brasileira de Direito Internacional, Curitiba, v.8, n.8, jul/dez.2008 


\subsection{O PROTOCOLO DE NOVA YORK DE 1967}

Tal diploma legal é de suma importância para o Direito Internacional dos Refugiados hodierno, haja vista que veio a complementar a Convenção de 1951, retirando reservas presentes nesta última.

Havia, assim, duas limitações na Convenção mencionada, uma de ordem geográfica e outra de ordem temporal.

A primeira referia-se à exigência de que o indivíduo que buscasse refúgio o fizesse em razão de perseguições ocorridas no interior do continente europeu. A segunda, por sua vez, dizia respeito à necessidade de tais perseguições se darem antes de $1^{\circ}$ de janeiro de 1951.

Há uma razão histórica para isto, já aludida anteriormente. A Convenção de 1951 foi elaborada para a problemática gritante e urgente dos refugiados na Segunda Grande Guerra. Pensava-se, mais uma vez, que a questão seria pontual e passageira. ${ }^{18}$

No mais, o Protocolo de 1967 manteve intacta a definição de refugiado.

Conforme David WHITTAKER, o Protocolo de 1967 transformou a Convenção Relativa ao Estatuto dos Refugiados de um documento legislativo fixado num momento histórico específico em um instrumento de direitos humanos ${ }^{19}$.

\section{AS DEFINIÇÕES AMPLIADAS}

São dois os instrumentos internacionais que ampliam a definição de refugiado, trazendo à tona outros elementos que podem motivar a fuga de um indivíduo de seu país de origem, nacionalidade ou residência habitual.

\footnotetext{
18 JUBILUT, Liliana Lyra. O Direito Internacional dos Refugiados e sua aplicação no ordenamento jurídico brasileiro. p. 85.

${ }^{19}$ WHITTAKER, David. Asylum seekers and refugee in the contemporary world. p. 5.
}

Revista Brasileira de Direito Internacional, Curitiba, v.8, n.8, jul/dez.2008 
O primeiro diploma a ser mencionado é a Convenção Relativa aos Aspectos dos Refugiados Africanos, adotada em 1969 pela Organização da Unidade Africana.

Nestes termos, a Convenção própria dos refugiados africanos considera não apenas os motivos expressos na Convenção de 1951 no que tange à definição dos refugiados, mas acrescenta outras razões que podem mover um demandante de refúgio, como atos de agressão, ocupação e dominação estrangeira, ou qualquer outro acontecimento que signifique grave perturbação da ordem pública ${ }^{20}$. A definição ampliada, neste caso, traz como vetor de impulsão essencialmente as guerras de descolonização ocorridas no continente africano, especialmente a partir dos anos 50.

Outro documento de importância memorável para a ampliação do conceito de refugiado é a Declaração de Cartagena, de 1984. Ela, do mesmo modo que a Convenção da Unidade Africana, inclui os motivos elencados na Convenção de 1951, porém considera também como refugiados:

“... as pessoas que tenham fugido dos seus países porque a sua vida, segurança ou liberdade tenham sido ameaçadas pela violência generalizada, a agressão estrangeira, os conflitos internos, a violação maciça dos direitos humanos ou outras circunstâncias que tenham perturbado gravemente a ordem pública". ${ }^{21}$

Diante deste novo conceito, deve-se ter em conta o que bem percebe JUBILUT:

\begin{abstract}
Apesar de representar uma evolução significativa, a aplicação da grave e generalizada violação de direitos humanos como motivo para o reconhecimento do status de refugiado é limitada tanto geográfica, em função de ter sido adotada por instrumentos regionais, quanto politicamente, pois os critérios para definir a caracterização de uma situação como de grave e generalizada violação de direitos humanos não são objetivos, deixando a questão da proteção dos refugiados mais uma vez sujeita à vontade política e discricionariedade de cada Estado $^{22}$.
\end{abstract}

Além do mais, embora a Declaração de Cartagena ofereça um avanço sensível no tocante às causas que podem ser invocadas por um demandante

\footnotetext{
${ }^{20}$ Artigo $1, \S 2^{\circ}$. da Convenção Relativa aos Aspectos dos Refugiados Africanos.

${ }^{21}$ Artigo 3‥ da Declaração de Cartagena (1984). Grifo nosso.

22 JUBILUT, Liliana Lyra. Op cit. p. 135.
} 
de refúgio para que obtenha proteção, não se pode olvidar o fato de que a Declaração de Cartagena, justamente por ser apenas uma declaração, não configurando um tratado, não constitui documento juridicamente vinculante. De todo o modo, consoante o ACNUR, a despeito disto, a maior parte dos países da América Latina incorporaram os princípios da Declaração de 1984 em suas legislações nacionais, tornando-os, assim, vinculantes no plano interno. ${ }^{23}$

\section{OS NOVOS REFUGIADOS}

Tendo por referência tudo o que foi exposto, apontam-se aqui dois exemplos, não exaustivos, de grupos de migrantes forçados, que chegam a transpor as fronteiras de seus países em busca de proteção, e que não são albergados pela Convenção de 1951, por não se enquadrarem no conceito formal de refugiado presente neste tratado. Trata-se, pois, dos denominados "refugiados ambientais" e "refugiados econômicos".

Fato é que estas categorias de migrantes forçados não são ainda oficialmente reconhecidas. Contudo, as discussões referentes a esta nova problemática a ser enfrentada pelo Direito Internacional dos Refugiados têm se proliferado nos tempos atuais, chamando a atenção para o enrijecimento do diploma legal por excelência de proteção aos refugiados. O resultado de tal enrijecimento não poderia ser outro a não ser milhões de pessoas totalmente à margem do sistema nacional e internacional de proteção à pessoa humana. $\mathrm{E} 0$ que é pior: por não se encaixarem numa definição formal e pretérita do que venha a ser um refugiado.

Embora nem os refugiados ambientais nem os refugiados econômicos sejam categorias oficialmente reconhecidas, eles já vêm recebendo atenção por boa parte da doutrina. Paulo Borba CASELLA é taxativo ao considerar três fatores que podem ensejar fluxos de refugiados: políticos, ambientais e econômicos ${ }^{24}$.

\footnotetext{
${ }^{23}$ UNHCR. Détermination du statut de réfugié... Op cit. p. 8.

${ }^{24}$ CASELLA, Paulo Borba. Refugiados: conceito e extensão. In: ALMEIDA, Guilherme Assis de; ARAUJO, Nadia de. O Direito Internacional dos Refugiados: uma perspectiva brasileira. $p$. 23.
}

Revista Brasileira de Direito Internacional, Curitiba, v.8, n.8, jul/dez.2008 
Admitindo-se que os refugiados por motivos políticos já se encontram amparados pela Convenção de 1951, tratar-se-á adiante dos refugiados ambientais e econômicos.

\subsection{OS REFUGIADOS AMBIENTAIS}

De acordo com Achim STEINER, diretor do Programa das Nações Unidas para o Meio Ambiente (PNUMA), a migração humana é uma das principais conseqüências da degradação ambiental e das mudanças climáticas dos últimos anos. ${ }^{25}$

Andrew MORTON, Philippe BONCOUR e Frank LACZKO reconhecem que "migrantes ambientais" constituem-se de "indivíduos, comunidades ou sociedades que escolhem, ou são forçados, a migrar, como resultado da degradação ambiental ou das mudanças climáticas. ${ }^{26}$ Seriam, portanto, refugiados ambientais aqueles indivíduos que cruzam as fronteiras de seu país, por temor de ameaça às suas vidas e/ou liberdades, em razão de secas, inundações, terremotos e outras catástrofes da natureza.

De acordo com o PNUMA, bem lembrado por Júlia Zanini de Gouveia PINTO27:

Refugiados ambientais são pessoas que foram obrigadas a abandonar temporária ou definitivamente a zona onde tradicionalmente vivem, devido ao visível declínio do ambiente (por razões naturais ou humanas) perturbando a sua existência e/ou a qualidade da mesma de tal maneira que a subsistência dessas pessoas entra em perigo.

Com o declínio do ambiente quer se dizer, o surgimento de uma transformação no campo físico, químico e/ou biológico do ecossistema, que, por conseguinte, fará com que esse meio ambiente temporária ou permanentemente não possa ser utilizado ${ }^{28}$.

Liliana JUBILUT salienta que a expressão "refugiados ambientais" foi

cunhada em 1985, mas apenas recentemente, com a ocorrência inúmeros

${ }^{25}$ STEINER, Achim. Climate change and displacement. p.4. In: Forced Migration Review. Refugee Studies Center, Oxford. Outubro, 2008.

${ }^{26}$ MORTON, Andrew, BONCOUR, Philippe; LACZKO, Frank. Human security policy challenges. In: Forced Migration Review. Refugee Studies Center, Oxford. Outubro, 2008. Tradução livre. Grifo nosso.

${ }^{27}$ PINTO, Júlia Zanini de Gouveia. Refugiados: análise das políticas públicas nacionais face ao Direito Internacional. p. 83.

28 LISER. Refugiados Ambientais. Disponível em: <http://www.liser.org/liser_portugesa.htm\#Definicao>. Acesso em: 02 fev. 2009.

Revista Brasileira de Direito Internacional, Curitiba, v.8, n.8, jul/dez.2008 
desastres naturais, como tsunamis, desertificação e outros, passou a haver uma pressão da comunidade internacional para que tais pessoas sejam albergadas pela proteção do Direito Internacional dos Refugiados ${ }^{29}$.

Aliás, a partir do momento em que indivíduos são forçados a deixarem seus países ou seus locais de residência habitual, por instinto de sobrevivência, configura-se o status de refugiados. Sabe-se que a concessão do refúgio tem natureza declaratória, e não constitutiva, do status de refugiado, já que os motivos que levaram o indivíduo à fuga já estavam presentes antes do reconhecimento oficial do status de refugiado ${ }^{30}$.

As causas das tragédias que vivem os refugiados ambientais podem ser as mais diversas: desde naturais, como vulcões e terremotos, até decorrentes da ação humana, como acidentes nucleares e guerras biológicas ${ }^{31}$.

São ainda MORTON, BONCOUR e LACZKO que reconhecem que o emprego do termo "refugiado", e, por extensão, do arcabouço político-jurídico convocado por esta expressão, é alvo de muitas objeções, já que a Convenção de 1951 concebe como realidade que subjaz a situação dos refugiados um cenário de violência ou intimidação política. ${ }^{32}$ Contudo, Flávia PIOVESAN bem lembra autores como David Carliner, Lucas Guttentag e Arthur Helton, os quais partilham da idéia de que o estado de perseguição, uma das condições sine qua non para que se reconheça a situação de refugiado, configura-se como "uma ameaça à vida ou à liberdade individual. Sob certas circunstâncias, a discriminação ou a negação de direitos básicos podem constituir perseguição ${ }^{33 ” . ~ E ~ e ́ ~ a ~ p a r t i r ~ d e s t e ~ e n t e n d i m e n t o ~ m a i s ~ e l a s t e c i d o ~ d o ~ q u e ~ v e n h a ~ a ~}$ ser perseguição, que se advoga a possibilidade de alargamento da Convenção de 1951 Relativa ao Estatuto dos Refugiados, sem que seja erodido o instituto do refúgio.

29 JUBILUT, Liliana. Op cit. p. 169.

${ }^{30}$ FILHO, José Francisco Sieber Luz. Non-refoulement: breves considerações sobre o limite jurídico à saída compulsória do refugiado. In ALMEIDA,Guilherme Assis de; ARAÚJO, Nadia de. O Direito Internacional dos Refugiados: uma perspectiva brasileira. p. 177.

${ }_{31}$ LISER. Refugiados Ambientais. Disponível em: <http: $<\mathrm{http}: / /$ www.liser.org/liser_portugesa.htm\#Definicao>. Acesso em: 02 fev. 2009.

${ }^{32}$ MORTON, Andrew et tal. Op cit. p. 5.

33 PIOVESAN. Flávia. $O$ direito de asilo e a proteção internacional dos refugiados. In: ALMEIDA, Gulherme Assis; ARAUJO, Nadia de. Op cit. p. 34.

Revista Brasileira de Direito Internacional, Curitiba, v.8, n.8, jul/dez.2008 
Seja como for, BONCOUR, MORTON e LACZKO entendem que as mudanças climáticas hão de reforçar de forma sem precedentes os fluxos de refugiados. Em primeiro lugar, pelos efeitos desastrosos das secas e inundações sobre a agricultura; em segundo, pela destruição de várias cidades litorâneas pelo aumento dos níveis dos mares, com tremendas perdas não só materiais, como também humanas ${ }^{34}$. A situação é agravada ainda com o comprometimento da capacidade de os habitantes de uma região extraírem comida, água e abrigo de ecossistemas devastados pelas mudanças climáticas.

São estes autores, aliás, que estimam, a partir de estudos acadêmicos e de agências internacionais, que haverá dezenas de milhares de refugiados ambientais nos próximos vinte anos e centenas de milhares nos próximos cinqüenta anos. ${ }^{35}$ É Oil BROWN quem traz à tona a estimativa do Programa das Nações Unidas para o Meio Ambiente (PNUMA), segundo o qual em 2060 poderá haver cerca de 50 milhões de refugiados ambientais tão somente na África. ${ }^{36}$

O Dicionário de Direitos Humanos segue a mesma linha, asseverando:

A ONU calcula que dentro de cinco anos 50 milhões de pessoas vão ser consideradas refugiadas devido a problemas ambientais nas regiões onde vivem e provavelmente chegue a 150 milhões até o ano 2050. Referido estudo da Universidade das Nações Unidas estima que hoje já existem tantos refugiados ambientais quanto pessoas que são forçadas a deixar suas casas por causa de distúrbios políticos ou sociais ${ }^{37}$.

Podem-se apontar exemplos de tão caótica situação. No Alasca, as temperaturas aumentaram cerca de 3,5․ Celsius desde 1974. Conseqüentemente, o Mar Ártico vem progressivamente aumentando seus níveis de água. O fenômeno significa uma verdadeira crise humanitária para as comunidades indígenas locais. Estima-se que esta catástofre pode submergir

\footnotetext{
${ }^{34}$ MORTON, Andrew et tal. Op cit. p. 6.

${ }^{35}$ Ibidem. p. 7.

${ }^{36}$ BROWN, Oil. The numbers game. In: Forced Migration Review. Refugee Studies Center, Oxford. Outubro, 2008. p. 8.

${ }_{37}$ Dicionário de Direitos Humanos. Refugiados Ambientais. Disponível em:<http://www.esmpu.gov.br/dicionario/tiki-index.php?page=Refugiado+Ambiental>. Acesso em 02 fev. 2009. Grifo nosso.
}

Revista Brasileira de Direito Internacional, Curitiba, v.8, n.8, jul/dez.2008 
comunidades inteiras ali instaladas, como os Kivalina e Shishmaref, nos próximos 15 anos $^{38}$.

O Quênia é outro exemplo dramático. O principal motivo ambiental de migração forçada reside nas secas prolongadas. A maior parte dos migrantes constitui-se de pastores, os quais migram em busca das chuvas, particularmente para a Somália e a Etiópia ${ }^{39}$. A tendência é que fiquem à margem da sociedade local.

As ilhas do Pacífico Sul também estão em alerta. Devido a sucessivas inundações, os moradores têm abandonado seus lares e migrado. Com o aumento do nível do mar, devido ao aquecimento global, Kiribati e Tuvalu podem ser engolidos pelo mar, saindo do mapa de vez até o fim deste século ${ }^{40}$.

O que fica claro da afirmação acima é que as catástrofes ambientais podem ser uma causa das mais significativas no que tange aos fluxos de refugiados, na medida em que os migrantes transponham fronteiras nacionais em busca de uma vida segura e digna. A comunidade internacional não pode insistir na negligência para com este assunto.

A despeito das previsões, estatísticas e exemplos fáticos, o status de "refugiado ambiental" está longe de ser um ponto pacífico na doutrina e nas agências oficiais.

Em favor da ampliação da Convenção de 1951, tendo em vista a proteção aos refugiados ambientais, residem autores como Scott LECKIE. Para ele, dever-se-ia privilegiar a evolução do Direito Internacional dos Refugiados, alargando a Convenção de 1951 por meio de um protocolo que permita aos refugiados ambientais serem protegidos pelo arcabouço político-jurídico de proteção aos refugiados já existente. ${ }^{41}$

Seguem a mesma esteira autores como Walter KALIM e Claudine DALE, para os quais o direito mais fundamental, o direito à vida, persiste sendo

${ }^{38}$ BRONEN, Robin. Alaskan communities : rights and resilience. In : Forced Migration Review. Refugee Studies Center, Oxford. Outubro, 2008. p. 30.

${ }^{39}$ ADOW, Mohamed. Pastoralists in Kenya. In : Forced Migration Review. Refugee Studies Center, Oxford. Outubro, 2008. p. 34.

40 PLANETA SUSTENTÁVEL. Países em extinção. Disponível em: $<$ http://planetasustentavel.abril.com.br/noticia/ambiente/conteudo_222280.shtml>. Acesso em 05 fev. 2009.

${ }^{41}$ LECKIE, Scott. Human rights implications. In : Forced Migration Review. Refugee Studies Center, Oxford. Outubro, 2008. p. 19.

Revista Brasileira de Direito Internacional, Curitiba, v.8, n.8, jul/dez.2008 
um dever do Estado, ainda que ameaçada ou posta a termo por catástrofes naturais. Nesta lógica, a violação sistemática a direitos humanos, como à vida e à liberdade, deve ser considerada autêntica perseguição e, por isso, dar espaço para que o indivíduo goze de proteção internacional, por meio do instituto do refúgio. Os autores reconhecem, de todo o modo, que esta percepção demanda uma renovação do quadro normativo do Direito Internacional dos Refugiados. ${ }^{42}$

Entendimento antagônico é encabeçado pelo próprio ACNUR. A Agência da ONU reconhece que os fluxos migratórios foram substancialmente alterados nos últimos anos, contudo, a Convenção de 1951 prosseguiria atual, na medida em que nos últimos 50 anos fora capaz de assistir mais de 50 milhões de pessoas em situações de crise muito variáveis. ${ }^{43}$ Como fica fácil de perceber, este argumento é extremamente retórico: não há lógica em se afirmar a atualidade de um instituto jurídico assegurando os seus méritos no passado.

Ray WILKINSON defende a mesma tese de que a Convenção de 1951 não carece de ser alargada em favor dos refugiados ambientais. $O$ autor justifica seu posicionamento alegando que as vítimas de catástrofes ambientais não deixam de gozar da proteção e do vínculo político-jurídico que mantêm com seus Estados de origem ou de nacionalidade e aí reside a diferença em relação aos refugiados acobertados pela Convenção de $1951^{44}$. E como se sabe, a proteção internacional é, por natureza, subsidiária em relação à proteção nacional, logo, se um Estado assiste seus cidadãos, é ilegítima a intervenção alienígena.

WILKINSON acresce ainda que a confusão entre os indivíduos que migram em razão de catástrofes ambientais e refugiados contribui para 0 enfraquecimento da proteção a estes grupos vulneráveis. Ele disserta:

\footnotetext{
${ }^{42}$ DALE, Claudine Haenni;KALIM, Walter. Disaster risk mitigation: why human rights matter. In : Forced Migration Review. Refugee Studies Center, Oxford. Outubro, 2008. p. 39.

${ }^{43}$ UNHCR. Le rempart érigé pour protéger les réfugiés : la Convention de 1951. p. 16.

${ }^{44}$ WILKINSON, Ray. Migrants écologiques et réfugiés. Des millions de personnes fuient des catastrophes naturelles. Sont-elles aussi des réfugiés ? In : UHNCR. Environnement : I'heure est à l'urgence. p. 12.
}

Revista Brasileira de Direito Internacional, Curitiba, v.8, n.8, jul/dez.2008 
Regrouper tout le monde dans la même catégorie ne ferait que compliquer les problèmes et entraverait les efforts déployés à la fois pour aider et protèger migrants écologiques et réfugiés et s'attaquer aux causes profondes ${ }^{45}$.

Ora, este argumento também se mostra bastante frágil. Não há como se garantir que, quando de uma catástrofe da natureza que dê ensejo a um fluxo migratório transfronteiriço, o Estado de origem ou de nacionalidade dos cidadãos continue a assisti-los integral e eficazmente.

De todo o modo, é brilhante a conclusão de Srgjan Kerim, quando presidente da Assembléia Geral das Nações Unidas, lembrada por Júlia Zanini de Gouveia PINTO ${ }^{46}$ : "Os refugiados do clima não são mais uma teoria, são uma triste realidade ${ }^{47 " \text {. }}$

\subsection{OS REFUGIADOS ECONÔMICOS}

Paulo Borba CASELLA define o refugiado econômico como aquele que "se vê diante da impossibilidade total de satisfazer suas necessidades vitais no país do qual é nacional". Neste contexto se faz necessária a diferenciação em relação ao migrante econômico, o qual, para o mesmo autor, "poderia, ao menos em tese, subsistir em seu país natal, mas, insatisfeito com as condições locais, se desloca para outra região, em busca de melhores perspectivas". ${ }^{4}$

O que chama a atenção à primeira vista é que o migrante econômico se caracteriza exatamente pela voluntariedade em sua migração; ao contrário do que ocorre com o refugiado econômico, o qual é forçado ou impelido a deixar seu país de origem ou de nacionalidade, pela total impossibilidade de satisfazer suas necessidades vitais básicas. O refugiado econômico, portanto, é movido pelo instinto de sobrevivência, enquanto o migrante, pelo desejo de melhorar suas condições de vida.

\footnotetext{
${ }^{45}$ Ibidem. p. 13. "Reagrupar todo mundo na mesma categoria não fará mais que complicar os problemas e entravar os esforços empregados para ajudar e proteger os migrantes ambientais e os refugiados e atacar as causas profundas" (tradução nossa).

${ }^{46}$ PINTO, Júlia Zanini de Gouveia. Op cit. p. 84.

47 PLANETA SUSTENTÁVEL. Os refugiados do clima já são uma realidade. Disponível em: $<$ http://planetasustentavel.abril.com.br/blog/redacao/92167_post.shtml> Acesso em: 02 fev. 2009.

${ }^{48}$ CASELLA, Paulo Borba. Op cit. p. 24.
}

Revista Brasileira de Direito Internacional, Curitiba, v.8, n.8, jul/dez.2008 
Assim, estender o Direito Internacional dos Refugiados aos migrantes econômicos representaria a erosão daquele sistema tão caro e valioso de proteção à pessoa humana. Em situação diversa se encontram os refugiados econômicos, carentes de proteção internacional, justamente por migrarem forçosamente, em busca de satisfação das suas necessidades vitais mais elementares, como a alimentação.

Jean ZIEGLER é o principal defensor do reconhecimento desta nova categoria de refugiados. ZIEGLER é relator da Comissão de Direitos Humanos das Nações Unidas para o Direito à Alimentação e advoga a extensão da proteção jurídica aos refugiados aos, assim, denominados por ele, "refugiados da fome".

Conforme o relator, é necessário reconhecer como autênticos refugiados aqueles indivíduos que deixam seus países de origem ou de nacionalidade por conta de graves crises alimentares que põem em risco a vida de milhares de cidadãos. Contudo, consoante este pensador, a proteção político-jurídica deveria ser temporária, isto é, enquanto durasse a crise alimentar por que passa o país de origem ${ }^{49}$.

Seuls les immigrants pouvant démontrer qu'ils viennent d'un pays traversant une crise alimentaire seraient admis. Une fois l'état d'urgence passé, ils pourraient être renvoyés dans leur pays ${ }^{50}$.

O próprio Relator da Comissão das Nações Unidas para o Direito à Alimentação reconhece a dificuldade de se fazer uma diferenciação clara e objetiva entre aqueles indivíduos que deixam seus países por estritas necessidades vitais e aqueles que o fazem com vistas a melhorar suas condições de vida. ${ }^{51}$ E é ZIEGLER quem declara: "A Convenção de 1951 já foi de tal forma atacada que uma revisão abriria a caixa de Pandora" ${ }^{52}$

${ }^{49}$ RÉFUGIÉS DE LA FAIM : un article terriblement accusateur de Jean Ziegler. Disponível em : <http://amapduperelachaise.free.fr/spip.php?article110 >. Acesso em: 31 ago. 2008.

${ }_{50}$ RÉFUGIÉS DE LA FAIM. Jenevois Blogspot. Disponível em : $<$ http://jenevois.blogspot.com/2007/06/rfugis-de-la-faim.htm>. Acesso em: 29 ago. 2008. "Apenas os imigrantes podendo provar que vêm de um país atravessando uma crise alimentar seriam admitidos. Uma vez que o estado de emergência passasse, eles poderiam ser reenviados aos seus países". (tradução nossa).

${ }^{51}$ PETITE, Simon. "Les réfugiés de la faim": nouveau cheval de bataille de Jean Ziegler. Disponível em

Revista Brasileira de Direito Internacional, Curitiba, v.8, n.8, jul/dez.2008 
Destarte, ZIEGLER tem o mérito de analisar a realidade dos refugiados para além da moldura formal e legalista do Direito Internacional dos Refugiados já consolidado. Não obstante, parece irrazoável defender o reconhecimento de uma nova categoria de refugiados, os refugiados econômicos, porém apenas de forma temporária, enquanto durasse uma crise alimentar no país de origem ou de nacionalidade do migrante. Assim, aqueles indivíduos que deixam seus países, por absoluta impossibilidade de satisfazer suas necessidades econômicas básicas, continuariam à margem de qualquer assistência, em não passando o país oficialmente por uma "grave crise alimentar". ZIEGLER parece não atentar para o pauperismo crônico que assola grande parte do mundo. $E$ vale lembrar que hoje existem cerca de 854 milhões de pessoas subnutridas no mundo ${ }^{53}$, por conta não de crises alimentares temporárias, mas de miséria absoluta e endêmica.

\section{A NECESSIDADE DE AMPLIAÇÃO DA CONVENÇÃO DE 1951 EM FACE DA INTERAÇÃO ENTRE OS DIREITOS HUMANOS E OS DIREITOS DOS REFUGIADOS.}

O que se quer afirmar, portanto, é a necessidade de ampliação da Convenção de 1951 Relativa ao Estatuto dos Refugiados, em prol destes grupos de migrantes que ficam à margem de qualquer proteção nacional e também internacional, restando completamente desassistidos. $E$ a ampliação se justifica com base no fato de que quando deixam seus países, impelidos pelo instinto de sobrevivência ou de preservação da sua liberdade, aí se observa a materialidade do status de refugiado.

É preciso ter em conta que a Convenção de 1951 foi elaborada num contexto em que se atentavam ainda apenas para os chamados direitos humanos de primeira geração, isto é, aqueles ligados às liberdades civis e

$<$ http://www.lecourrier.ch/index.php?name=NewsPaper\&file=article\&sid=436773>. Acesso em 31 ago. 2008.

52 Ibidem. Tradução nossa.

${ }^{53}$ Ibidem.

Revista Brasileira de Direito Internacional, Curitiba, v.8, n.8, jul/dez.2008 
políticas. Daí a proteção ao indivíduo que sofresse perseguição em razão de suas opiniões políticas, sua religião, sua nacionalidade e assim por diante.

Contudo, contemporaneamente, a temática dos direitos humanos tornou-se significativamente mais complexa. Prova disto é que hoje se fala em direitos humanos de segunda geração, isto é, os direitos econômicos, sociais e culturais, como o direito ao trabalho, à greve, à sindicalização e outros. Fala-se também em direitos humanos de terceira geração, ou ainda, os direitos de solidariedade, tais como o direito ao meio ambiente sadio e equilibrado, o direito à paz, ao desarmamento nuclear etc. Paulo BONAVIDES defende ainda a categoria de direitos humanos de quarta geração, de que seria exemplo o direito à democracia direta ${ }^{54}$.

CANÇADO TRINDADE, de forma muito lúcida, mostra-se contrário a esta compartimentalização dos direitos humanos em direitos de primeira, segunda e terceira geração. Isto porque, o que ocorre não é uma sucessão de gerações de direitos, mas sim um acúmulo e uma transformação destes últimos. Ele esclarece:

A noção simplista das chamadas "gerações de direitos" tem prestado um desserviço ao pensamento mais lúcido a inspirar a evolução do Direito Internacional dos Direitos Humanos. Distintamente do que a infeliz invocação da imagem analógica da "sucessão geracional" pareceria supor, os direitos humanos não se sucedem ou substituem uns aos outros, mas antes se expandem, se acumulam e fortalecem, interagindo os direitos individuais e sociais ${ }^{55}$.

Ademais, com vistas a uma concepção suficientemente holística da realidade, é preciso ter em conta que o Direito Internacional dos Direitos Humanos, do qual o Direito Internacional dos Refugiados é um ramo especializado, constitui um todo único, uno, indivisível. $\mathrm{Na}$ Segunda Conferência Mundial dos Direitos Humanos das Nações Unidas, em Viena, no ano de 1993, restou expresso: "Só se pode conceber o Direito dos Refugiados no âmbito dos Direitos Humanos, de que é um ramo especializado ${ }^{56 " . ~ N a ̃ o ~ h a ́, ~}$

\footnotetext{
${ }^{54}$ Lembrado pela Professora Eneida Desirée Salgado, em aula da Cadeira de Direito Eleitoral, na Universidade Federal do Paraná, 2008.

55 CANÇADO, Antônio Augusto Cançado. Tratado de Direito Internacional dos Direitos Humanos. p. 25.

${ }^{56}$ Idem. p. 334.
}

Revista Brasileira de Direito Internacional, Curitiba, v.8, n.8, jul/dez.2008 
pois, cabimento em se conceber a proteção aos indivíduos que são forçados a deixarem seu país de origem ou de nacionalidade apenas no âmbito das violações dos direitos civis e políticos. O indivíduo é único, é um todo, cuja esfera jurídica de direitos humanos é indivisível. Daí a premente necessidade de se reconhecerem as violações dos direitos econômicos, sociais e culturais, e outros ainda, como fatores de ameaça à vida, à liberdade e à dignidade daquele que é forçosamente migrante. O próprio ACNUR reconhece que a "perseguição", fator essencial para o reconhecimento do status de refugiado, constata-se no risco de sério dano ao indivíduo, combinado com a falha do Estado no que tange à proteção ${ }^{57}$.

Como bem tratado pelo Professor CANÇADO TRINDADE, o Direito Internacional dos Direitos Humanos e o Direito Internacional dos Refugiados guardam a mais íntima e profunda relação. Aliás, ele conclui pela progressiva aproximação entre o Direito Internacional dos Direitos Humanos e o Direito Internacional dos Refugiados, em decorrência do "fenômeno contemporâneo de êxodos e fluxos maciços de pessoas ${ }^{58 ", ~ o ~ q u a l ~ d e m a n d a ~ a ~ c o n j u n c ̧ a ̃ o ~ d e ~}$ esforços dos instrumentos e instituições internacionais com vistas à proteção adequada da pessoa humana.

Além do mais, o respeito aos direitos humanos são a melhor forma de se prevenir os problemas dos refugiados ${ }^{59}$. Na verdade, de acordo com CANÇADO TRINDADE, a prevenção, a proteção e a solução das questões envolvendo refugiados passam pela observação dos direitos humanos ${ }^{60}$.

Com tudo isto se objetiva asseverar que a Convenção de 1951 carece de acompanhar a dinamicidade da ordem internacional contemporânea. $E$ é imperativo que novas regras de proteção aos indivíduos forçosamente deslocados de seus países em razão de catástrofes ambientais ou pauperismo crônico sejam albergadas num instrumento jurídico do porte da Convenção de 1951, diploma indubitavelmente vinculante para os Estados.

\footnotetext{
${ }^{57}$ WHITTAKER, David. Op cit. p.9.

58 TRINDADE, Antônio Augusto Cançado. Op cit. p. 322.

${ }^{59}$ Idem. p. 320.

${ }^{60}$ Idem. p. 347.
}

Revista Brasileira de Direito Internacional, Curitiba, v.8, n.8, jul/dez.2008 
Obviamente, não se desconsidera aqui o progresso do Direito Internacional dos Refugiados alcançado por meio da Convenção de 1951. Consorte Tony Blair, a Convenção de 1951 alberga valores atemporais ${ }^{61}$. De todo o modo, este documento, historicamente situado, fruto de um tempo e de um espaço específicos, pode e deve ser renovado, com fins a melhor se adequar às necessidades do mundo contemporâneo. Como bem explana WHITTAKER, em não se atentando para as novas necessidades, "Refugees may spend some time in orbit, knocking on closing doors ${ }^{62 "}$.

\section{A CONSTRUÇÃO ARTIFICIAL DO CONCEITO DE REFUGIADO}

Mais além, deve-se ter em conta que, como qualquer conceito jurídico, também o de refugiado passa por uma construção ideológica, a qual reflete o momento histórico do pós-Segunda Guerra Mundial e os interesses dos Estados, principalmente europeus, da época.

Especificamente no que toca à problemática dos refugiados, WHITTAKER é taxativo ao considerar que "a validade de uma definição depende em grande medida das perspectivas empregadas por aqueles que vão usar a definição ${ }^{63}$. É o mesmo que dizer: os conceitos, as definições, os enunciados, são todos artificiais e provisórios, e o alcance e utilidade destes elementos dependem das perspectivas dos sujeitos que os manipulam.

Como advoga Alf ROSS, influenciado por WIDDGENSTEIN, o Direito, e assim também o Direito Internacional, constitui verdadeiro jogo de linguagem, cujos significados são construídos de modo arbitrário e convencional. $\mathrm{O}$ autor rejeita, portanto, a tese de haver uma essência nos conceitos jurídicos, já que estes seriam construídos de modo artificial ao longo da história, podendo ser totalmente diferentes. ${ }^{64}$

Na linha de pensamento de David TURTON, os conceitos não significam a mera descrição de algum objeto de conhecimento que se encontra projetado

\footnotetext{
${ }^{61}$ WHITTAKER, David. Op cit. p. 12.

${ }^{62}$ Idem. p. 11. "Os refugiados podem gastar um tempo em órbita, batendo em portas fechadas" (tradução nossa).

${ }^{63}$ WHITTAKER, David. Op cit. p. 10. Tradução nossa.

${ }^{64}$ ROSS, Alf. Direito e Justiça.
}

Revista Brasileira de Direito Internacional, Curitiba, v.8, n.8, jul/dez.2008 
no mundo exterior, porém implicam verdadeira construção do objeto em questão. ${ }^{65}$ Assim, o conceito de refugiado, e o próprio Direito Internacional dos Refugiados, não é algo que se descobre, mas algo que se constrói cultural e historicamente.

É o mesmo autor quem frisa que quando se trata da problemática de refugiados, é comum se empregarem expressões como "fluxos", "correntes", "inundação", entre outras, as quais não são inocentes, mas carregam uma carga ideológica pejorativa ${ }^{66}$, sugerindo algo que invade o território alheio e tão somente perturba a realidade e traz prejuízos.

Aliás, é importante destacar que esta não é a linguagem dos próprios refugiados. A perspectiva difundida é a estatocêntrica. Quer dizer, a sociedade internacional tem adotado uma posição de exterioridade em relação a este grupo social, preferindo a distância, em nome do formalismo.

CANÇADO TRINDADE, citando J.J. Olivier, lembra que: "ficções são usadas em todos os ramos do direito e muitas vezes tornam-se a tal ponto arraigadas no sistema jurídico que não mais são reconhecidas como ficções ${ }^{67 " .}$.

\section{CONCLUSÃO}

Diante de tudo o que se explanou, resta concluir, de início, que a Convenção de 1951 Relativa ao Estatuto dos Refugiados implicou profundo avanço no que tange à proteção político-jurídica estendida aos refugiados.

Em se constituindo de um documento juridicamente vinculante, de âmbito universal, sua importância é tremenda, na medida em que estabeleceu a responsabilidade de todos os Estados-partes quanto à proteção dos refugiados.

Não se pode desconsiderar, todavia, que os instrumentos jurídicos carecem de acompanhar a dinamicidade da ordem social. E é neste contexto que se percebe a urgência em se renovar o Direito Internacional dos

\footnotetext{
65 TURTON, David. Conceptualising forced migrations.

${ }^{66}$ Idem. p. 4.

67 TRINDADE, Antônio Augusto Cançado. O Direito Internacional em um mundo em transformação. p. 165.
}

Revista Brasileira de Direito Internacional, Curitiba, v.8, n.8, jul/dez.2008 
Refugiados, e, mais especificamente, a Convenção de 1951, em vistas a um conceito mais elastecido de refugiado. Nesta lógica, os refugiados ambientais e econômicos são apenas dois exemplos de novos grupos de migrantes forçados que atravessam as fronteiras nacionais e restam carentes de proteção internacional. Porém, justamente por conta da dinamicidade mencionada, sabese que no futuro, outros refugiados surgirão e o Direito Internacional dos Refugiados deve estar preparado para lidar com a sua necessária flexibilidade.

$E$, em verdade, tal flexibilidade é imperativa no sistema internacional hodierno, caracterizado pela supremacia dos direitos humanos e pela relativização das soberanias estatais em vistas a se erigir a proteção à pessoa humana como norte teleológico dos sistemas jurídicos nacionais e internacional. Aliás, isto implica uma opção política, que reflete uma escolha por determinados valores.

Como assegura CANÇADO TRINDADE, o reconhecimento da centralidade dos direitos humanos é o novo ethos dos nossos tempos. ${ }^{68}$ Neste diapasão, diz ele, "O ser humano passa a ocupar, em nossos dias, a posição central que lhe corresponde, como sujeito de direito tanto interno quanto internacional". 69

\section{REFERÊNCIAS}

ALMEIDA, Guilherme Assis de; ARAUJO, Nadia de. (coord).O Direito Internacional dos Refugiados: uma perspectiva brasileira. Rio de Janeiro: Renovar, 2001.

ANDRADE, José H. Fischel de. Direito Internacional dos refugiados: evolução histórica (1921-1952). Rio de Janeiro: Renovar, 1996.

DICIONÁRIO DE DIREITOS HUMANOS. Refugiados Ambientais. Disponível em:<http://www.esmpu.gov.br/dicionario/tikiindex.php?page=Refugiado+Ambiental>. Acesso em 02 fev. 2009.

FORCED MIGRATION REVIEW. Climate change and displacement. Oxford, 2008.

\footnotetext{
68 TRINDADE, Antônio Augusto Cançado Trindade. A humanização do Direito Internacional. p. 112.

${ }^{69}$ Idem. p. 17.
}

Revista Brasileira de Direito Internacional, Curitiba, v.8, n.8, jul/dez.2008 
JUBILUT, Liliana Lyra. O Direito Internacional dos Refugiados e sua aplicação no ordenamento jurídico brasileiro. São Paulo: Método, 2007.

LISER. Refugiados Ambientais. Disponível em:

<http://www.liser.org/liser_portugesa.htm\#Definicao>. Acesso em: 02 fev. 2009.

ORGANIZAÇÃO DAS NAÇÕES UNIDAS. Convenção Relativa ao Estatuto dos Refugiados. Genebra, 1951.

PLANETA SUSTENTÁVEL. Países em extinção. Disponível em:

$<$ http://planetasustentavel.abril.com.br/noticia/ambiente/conteudo_222280.shtm l>. Acesso em 05 fev. 2009.

PINTO, Júlia Zanini de Gouveia. Refugiados: análise das políticas públicas nacionais face ao Direito Internacional. Monografia (Bacharelado em Direito). Centro Universitário Curitiba, Curitiba, 2008.

RÉFUGIÉS DE LA FAIM : un article terriblement accusateur de Jean Ziegler. Disponível em :<http://amapduperelachaise.free.fr/spip.php?article110>. Acesso em: 31 ago. 2008.

RÉFUGIÉS DE LA FAIM. Jenevois Blogspot. Disponível em : $<$ http://jenevois.blogspot.com/2007/06/rfugis-de-la-faim.htm>. Acesso em: 29 ago. 2008

ROSS, Alf. Direito e Justiça. São Paulo: Edipro, 2008.

SALDANHA, Eduardo. Teoria das Relações Internacionais. Curitiba: Juruá, 2006

PETITE, Simon. "Les réfugiés de la faim": nouveau cheval de bataille de Jean Ziegler. Disponível em :

$<$ http://www.lecourrier.ch/index. php?name=NewsPaper\&file=article \&sid=43677 3>. Acesso em 31 ago. 2008.

TRINDADE, Antônio Augusto Cançado. Tratado de Direito Internacional dos Direitos Humanos. Vol. 1. Porto Alegre: Sérgio Antônio Fabris Editor, 1997.

. O Direito Internacional em um mundo em transformação. Rio de Janeiro: Renovar, 2002.

. A humanização do Direito Internacional. Belo Horizonte : Del Rey, 2006.

TURTON, David. Conceptualising forced migration. Refugee Studies Center. University of Oxford. 2003.

Revista Brasileira de Direito Internacional, Curitiba, v.8, n.8, jul/dez.2008 
UNHCR. Détermination du statut de réfugié : déterminer qui est un réfugié. Modeule d'autoformation 2. Gèneve, 2005.

UNHCR. Environnement: I'heure est à l'urgence. Gèneve, 2008.

UNHCR. Introduction à la protection internationale : protèger les personnes relevant de la competénce du HCR. Module d'autoformation 1. Gèneve, 2005.

UNHCR. La Convention de 1951 relative au statut des réfugiés : questions et réponses. Gèneve, 2007.

UNHCR. Le rempart érigé pour protéger les réfugiés : la Convention de 1951. Gèneve, 2007.

WHITTAKER, David. Asylum seekers and refugee in the contemporary world. London and New York: Routledge Taylor \& Francis Group, 2006. 